\title{
Perspectivas para a formação de formadores de futuros professores no contexto das políticas públicas
}

\author{
Perspectives for development of educators of prospective teachers in the \\ public policies context \\ Perspectivas para la formación de formadores de futuros docentes en el \\ contexto de las políticas públicas
}

\author{
ADRIANA RICHIT \\ Orcid Id: http://orcid.org/0000-0003-0778-8198 \\ Universidade Federal da Fronteira Sul \\ WILLIAM XAVIER DE ALMEIDA \\ Orcid Id: http://orcid.org/0000-0001-5477-3373 \\ Universidade do Estado de Santa Catarina
}

\begin{abstract}
Resumo: $\mathrm{O}$ artigo discute as perspectivas para o desenvolvimento profissional de formadores de futuros professores a partir da análise do ordenamento legal relativo à formação de professores de nível superior e das ações e programas de agências vinculadas ao Ministério da Educação, vocacionadas ao ensino superior. $\mathrm{O}$ estudo se baseou nos conceitos de desenvolvimento profissional e profissionalidade docente, definidos por António Nóvoa, Maria do Céu Roldão e Selma Pimenta. A análise qualitativa e interpretativa incidiu sobre um conjunto de documentos oficiais compilados mediante uma busca criteriosa nos sites oficiais vinculados ao Ministério da Educação. Os documentos que constituíram o material empírico do estudo foram analisados e interpretados, a partir dos quais evidenciamos duas perspectivas de desenvolvimento profissional para o docente da educação superior: a universidade é lócus para o desenvolvimento do formador, quer seja como instância para realização de programas de pós-graduação, pósdoutorado, realização de parcerias institucionais e interinstitucionais, assim como por oportunizar ao professor formador diferentes experiências profissionais em nível de ensino e pesquisa; o desenvolvimento do formador se concretiza mediante a realização de pesquisa e produção de conhecimento, na medida em que os incentivos se concentram na distribuição de bolsas de pesquisa e pósgraduação e premiação de trabalhos de destaque.
\end{abstract}

Palavras-chave: Desenvolvimento profissional docente. Formadores de futuros professores. Políticas públicas. Educação superior.

\footnotetext{
Abstract: The article discusses the prospects for the professional development of prospective teachers' educators based on the analysis of the official documents related to the training of higher education teachers and the actions and programs of agencies linked to the Ministry of Education aimed at higher education. The study was based on the concepts of professional development and teaching professionality defined by António Nóvoa, Maria do Céu Roldão, and Selma Pimenta. The analysis, qualitative and interpretative, focused on a set of official documents recovered through a careful search on the official websites linked to the Ministry of Education. These documents, which constituted the empirical material of the study, were analyzed and interpreted, from which we highlight two perspectives of professional development
} 
for higher education teachers: the university is the locus for the educators' development, whether as an instance for carrying out post-graduate, post-doctoral programs, institutional and interinstitutional partnerships, as well as providing opportunities for different types of professional experiences at the level of teaching and research; the development of the educator is achieved through research and knowledge production, as the incentives are concentrated on the distribution of research and graduate scholarships and awards for outstanding work.

Keywords: Teacher professional development. Prospective teachers' educators. Public policy. Higher education.

Resumen: El articulo analiza las perspectivas para el desarrollo profesional de formadores de futuros docentes con base en el análisis del sistema legal relacionado con la formación de docentes de educación superior y las acciones y programas de agencias vinculadas al Ministerio de Educación dirigidas a la educación superior. El estudio se basó en los conceptos de desarrollo profesional y profesionalidad docente definidos por António Nóvoa, Maria do Céu Roldão y Selma Pimenta. El análisis, cualitativo e interpretativo, se centró en un conjunto de documentos oficiales compilados a través de una búsqueda cuidadosa en los sitios web oficiales vinculados al Ministerio de Educación. Estos documentos, que constituyeron el material empirico del estudio, fueron analizados e interpretados, desde los cuales destacamos dos perspectivas de desarrollo profesional para los docentes de educación superior: la universidad es el lugar para el desarrollo del capacitador, ya sea como una instancia para llevar a cabo programas de posgrado, posdoctorado, asociaciones institucionales e interinstitucionales, además de brindar oportunidades para diferentes tipos de experiencias profesionales en docencia e investigación; El desarrollo del capacitador se logra a través de la investigación y la producción de conocimiento, ya que los incentivos se concentran en la distribución de becas y premios de investigación y posgrado por un trabajo sobresaliente.

Palabras clave: Desarrollo profesional docente. Formadores de futuros docentes. Politicas públicas. Educación universitaria.

\section{INTRODUÇÃO}

Ensinar é uma atividade caracterizada pela constante tomada de decisão sobre $o$ que, porque e como ensinar, envolvendo a especificidade do conteúdo, os contextos nos quais o ensino é concretizado e as características dos sujeitos que aprendem e do conteúdo a ser ensinado (SOTO et al, 2020). Essa perspectiva valoriza o profissional professor e o coloca no centro das atenções e intenções dos projetos oficiais e não oficiais de formação (GATTI; BARRETO, 2009). Na esteira desse movimento, a centralidade dos processos formativos como base de uma prática docente qualificada tornou-se uma tendência consolidada nas distintas áreas do conhecimento ao redor do mundo, constituindo-se em uma importante frente de investimentos e ações que colocam a universidade como contexto e via de promoção de processos formativos e crescimento profissional. É nesse contexto que o conceito de "desenvolvimento profissional docente" assume relevância, fazendo emergir discussões sobre as dimensões subjacentes 
a este processo, tais como as políticas públicas e os conceitos de formação e de formação continuada de professores, assim como sobre os contextos em que esses processos se concretizam.

A formação docente, em seu sentido mais amplo, caracteriza o processo de concretização de aprendizagens profissionais relativas à docência, abarcando dimensões teóricas, ideológicas, políticas, sociais, culturais, epistemológicas e filosóficas da educação, bem como aquelas relativas a uma área específica do conhecimento. Nessa perspectiva, a formação docente abarca a formação inicial em nível de licenciatura e a formação continuada, que se refere ao processo de crescimento pessoal e profissional do professor ao longo da carreira. A formação continuada pode contribuir para a manutenção, criação e alteração das relações estruturantes e estruturadoras do desenvolvimento profissional dos professores (ALVARADO-PRADA, 2001) e, também, das práticas concretizadas por esses profissionais.

Gatti e Barretto (2009) e Zabalza (2004) compartilham a perspectiva de que a universidade é locus privilegiado e de excelência na formação profissional docente. Assumindo a universidade como espaço de aquisição de conhecimentos e desenvolvimento dos docentes, recai sobre o professor do ensino superior, especialmente aquele que atua nas licenciaturas, grande responsabilidade. É ele que, na academia, compromete-se em ensinar e orientar os estudantes, futuros docentes, nos seus percursos formativos. Nessa perspectiva, o processo formativo desse profissional, que é um processo de formação de formadores de professores, assume relevância e precisa ser refletido.

Assim como o docente da educação básica, o profissional da educação superior - incluindo aquele que trabalha como professor formador de futuros professores em cursos de licenciaturas - necessita apropriar-se de conhecimentos profissionais distintos e aprofundados de modo a desenvolver uma prática profissional coerente e qualificada. Nessa perspectiva, segundo Gatti e Barreto (2009), a formação continuada assume, então, um caráter processual de desenvolvimento profissional contínuo, apropriação de novos conhecimentos e aprofundamento de conhecimentos e práticas profissionais adquiridas.

Ponte (1994) e Nóvoa (1999) dialogam ao explicitarem a noção de desenvolvimento profissional docente como um processo formativo constante ao longo da carreira do professor, cujo objetivo consiste em dar continuidade às aprendizagens profissionais realizadas na formação inicial e aperfeiçoar os conhecimentos profissionais necessários à prática nos diferentes percursos e tempos da carreira docente. Ou seja, o desenvolvimento profissional é um processo contínuo ao longo da trajetória do(a) professor(a), que não se encerra 
sobre determinada formação ou titulação, tornando-se essencial a constante busca por processos que permitam a ampliação e revisão de práticas a partir da apropriação de novos conhecimentos.

Assumindo, portanto, que os processos formativos ao longo da carreira docente buscam, para além de suprir carências formativas da formação inicial, promover o desenvolvimento profissional do professor, a discussão sobre os elementos que caracterizam a profissionalidade docente reveste-se de relevância, pois segundo Roldão (2007), ser professor não é dom ou vocação: é profissão apoiada e legitimada por um complexo corpo de conhecimentos específicos necessários à prática docente.

Nesse sentido, Zabalza (2004) acrescenta que no atual cenário educacional, a formação inicial desempenha papel importante, mas não exclusivo nem prioritário no processo de formação profissional docente. Para este autor, a formação começa antes mesmo de o docente ingressar na graduação e se desenvolve dentro e fora de suas disciplinas e programas. Complementa que, pelo menos na Europa, já é comum as universidades possuírem mais estudantes de pós-graduação do que de graduação.

Mobilizados por esses aspectos, este artigo se dedica a examinar o aparato legal relativo à formação de professores que atuam na educação superior no Brasil, buscando identificar as perspectivas de desenvolvimento profissional para professores que atuam em cursos de licenciatura, isto é, formadores de futuros professores. Aqui nos debruçamos sobre formação de formadores de futuros professores, primeiramente porque há carência de trabalhos sobre essa temática no campo de investigação da educação. Além disso, no Brasil as últimas duas décadas foram muito profícuas em termos de investimentos e esforços para qualificar a formação de professores em diferentes níveis de ensino e áreas do conhecimento, concretizados por meio de uma série de políticas e programas oficiais.

\section{DESENVOLVIMENTO PROFISSIONAL E PROFISSIONALIDADE DOCENTE}

De acordo com Nóvoa (2003), a profissão docente se exerce a partir de uma adesão coletiva, implícita ou explícita, a um conjunto de valores e normas. Porém, quanto mais explícitos forem tais valores, mais fácil torna-se mitigar as margens de ambiguidade que marcam a profissão docente. Nessa perspectiva, quanto mais tácita é a concepção de profissionalidade docente adotada pelo profissional, maior será o entendimento de seus processos constitutivos enquanto docente. 
Para Roldão (2007), a docência, ou seja, o ato de ensinar é o que constitui a especificidade profissional do professor, sendo esta uma concepção relativamente estável ao longo do tempo, mesmo em face das profundas mudanças estruturais que a sociedade enfrenta. Acrescenta que o próprio conceito de ensinar também é socialmente construído e mutável. Entretanto, afirma que, transversalmente à épocas e a culturas, ensinar constitui-se como a mediação operada por alguém (docente) entre o conhecimento a ser adquirido (conteúdo, currículo) e o sujeito que aprende (aluno) (ROLDÃO, 2014). Emerge, no cerne dessa compreensão, a perspectiva do desenvolvimento profissional, concebido como elemento constituinte da profissionalidade docente.

Para Nóvoa (1999), não é possível imaginar uma mudança em qualquer cenário educacional que não perpasse a formação de professores. O autor chama a atenção para o fato de que é preciso entender formação não apenas como "programa de formação" ou meramente sequência de ações pontuais: é necessário reformular a concepção de formação, situando-a ao longo dos diferentes ciclos de vida e de carreira do professor, numa trajetória de desenvolvimento pessoal e profissional. Ou seja, integrar todas as dimensões e conhecimentos do trabalho pedagógico no cotidiano da profissão docente, tornando tais dimensões e conhecimentos essenciais à definição de cada docente como tal (NÓVOA, 1999).

Ponte (1994) ressalta o caráter de incompletude intrínseco à formação inicial docente. Para ele, o professor não se torna um profissional completo ao obter sua habilitação, pois as aprendizagens profissionais realizadas durante a formação inicial não são suficientes para o efetivo exercício de sua profissionalidade ao longo da carreira. Nessa direção, esclarece que o desenvolvimento profissional é, portanto, uma perspectiva de reconhecimento da necessidade de aquisições cognitivas diversas ao longo da carreira docente, processo este em que se atribui ao professor o papel de sujeito central. É neste movimento que o profissional se constitui professor de facto (PONTE, 1994).

Corroborando as ideias desses dois autores portugueses, as brasileiras Gatti e Barretto (2009) colocam-se a favor de uma ressignificação do que se entende por "formação continuada": uma reconceitualização que a remova da função exclusiva de preencher lacunas da formação inicial e a desloque para o espectro de atividades de promoção do potencial de crescimento do docente e de fortalecimento de sua prática e de sua própria identidade docente. 
O protagonismo do professor passa a ser valorizado e a ocupar o centro das atenções e intenções nos projetos de formação continuada. Novos modelos procuram superar a lógica de processos formativos que ignoram a trajetória percorrida pelo professor em seu exercício profissional. Nesta concepção de formação como um contínuo ao largo da vida profissional, o conceito subjacente é o de desenvolvimento profissional. O processo de formação é definido como um movimento orientado a responder aos diversos desafios que se sucedem no que se poderia identificar como diferentes fases da vida profissional: o início da carreira, o processo de desenvolvimento e os tempos mais avançados em que o professor consolida sua experiência profissional. (GATTI; BARRETTO, 2009, p. 202-203, grifo nosso).

De maneira similar, Marin (1995) enfatiza essa perspectiva, ao afirmar que a atividade profissional do professor é algo que se refaz continuamente, cotidianamente, mediante processos formativos formais e informais, sem dissociação nem dicotomia entre vida e trabalho, trabalho e lazer. Além disso, Ponte (1994) aponta para o caráter humano do processo formativo, cujo foco seja o desenvolvimento profissional, sugerindo que o professor não deve ser visto como mero receptáculo de conteúdos ou de estratégias de ensino destes. Deve, pois, ser encarado como sujeito ativo do processo de construção e reconstrução do conhecimento, com potencialidades e necessidades diversas a serem compreendidas e desenvolvidas.

Nessa perspectiva, a concepção de formação continuada transcende a dicotomia formação inicial-continuada, pois o amplo espectro de atividades, tanto institucionalizadas e formais, como espontâneas, a qualquer tempo de carreira, é entendido como processo formativo, dentro do contexto do desenvolvimento profissional docente. Portanto, pensar processos formativos com base nesse contexto significa fomentar ações e atividades em que o professor possa tornar-se sujeito ativo e central na apropriação de conhecimentos necessários à sua prática individual e social, mediante a mobilização do reconhecimento acerca de suas potencialidades e fragilidades.

\section{DESENVOLVIMENTO PROFISSIONAL E A FORMAÇÃO DE FORMADORES DE PROFESSORES}

A produção científica nacional revela certa dispersão conceitual acerca da temática "formação de formadores". Ora o termo é adotado para designar o processo de formação de futuros professores (graduandos de licenciatura), ora refere-se a formadores como quaisquer profissionais da educação - professores ou não - que atuam na promoção de formação continuada. No âmbito de nossos estudos, entretanto, nos referimos à formação de formadores de professores para 
designar o processo de formação continuada do docente universitário atuante em cursos de licenciatura, ou seja, formadores de futuros professores. Por outro lado, designar esse processo como formação continuada também é inadequado, uma vez que nos parece diminuir sua importância e centralidade dentro do conceito no qual nos apoiamos, de desenvolvimento profissional docente contínuo ao longo da carreira docente. Portanto, a designação que melhor caracteriza o processo de formação de formadores de professores, contínuo e permanente segundo, a perspectiva de Ponte (1994) e Nóvoa (1999), é o de desenvolvimento profissional de formadores de futuros professores.

Gatti e Barreto (2009) afirmam que a qualidade de qualquer atividade formativa tem relação com a formação adequada dos profissionais que atuam como formadores nessas atividades, por meio de seu domínio conceitual e prático e de seu envolvimento e compromisso com a formação de professores. Tal comprometimento com a formação de educadores requer, certamente, fortes e positivas concepções de formação e de profissionalidade docente, ou seja, daquilo que diferencia o professor de outros profissionais, bem como um domínio da ampla gama de conhecimentos que legitimam sua ação docente.

As autoras, entretanto, apontam que a formação continuada, em especial, carece de uma identidade sólida acerca de si própria e sobre o que é o ato de ensinar, de quais subsídios teóricos e práticos necessita. Para além disso, afirmam também que, na prática, muitas vezes os formadores não possuem os conhecimentos teóricos ou práticos necessários para ensinar os professores que estão formando. Desse modo, a formação de formadores converte-se em tópico de interesse, pois uma sólida formação dos formadores é essencial para o desenvolvimento de novas gerações docentes.

\footnotetext{
Os estudos e as investigações sobre processos formativos para o desenvolvimento profissional do professor indicam que o tema da formação dos formadores merece atenção. A qualidade da formação inicial e do desenvolvimento profissional dos professores tem relação com a preparação dos profissionais que atuam como formadores neste trabalho, seu domínio conceitual e prático e seu envolvimento e compromisso com a formação de educadores. (GATTI; BARRET'TO, 2009, p. 229).
}

Ainda de acordo com as autoras, mesmo quando os profissionais dedicados a preparar (formar) os futuros professores dominam saberes inerentes à formação docente, necessitam eles próprios de espaço e subsídios para sua formação e seu desenvolvimento, sendo essa uma limitação comumente observada nas pesquisas e que, segundo Gatti e Barretto (2009), pode ser superada com um trabalho integrado e institucional. 
Nessa perspectiva, é necessário que os professores tenham clareza de quais são as variáveis que interagem em sua prática docente. Mais do que isso: é preciso que os formadores de professores tenham clareza desses conhecimentos e possam embasar suas práticas neles, estimulando os futuros professores a também refletirem criticamente sobre as bases que compõem sua prática e que definem a profissionalidade da classe. Tal entendimento pode trazer reflexos positivos para as práticas dos formadores de professores, tais como maior articulação entre teoria e prática, revisão dos métodos e posturas avaliativas, maior consciência crítica a respeito do que se ensina e do porquê se ensina e, ainda, aprofundamento da compreensão sobre os elementos constituintes da profissionalidade docente.

Portanto, formação dos formadores de professores assume relevância, pois se constitui em espaço de aquisição de novos conhecimentos, socialização de novas práticas, reflexão sobre a docência e discussão do próprio processo de formação docente. Sobre isso, Zabalza (2004) concebe o espaço universitário como locus privilegiado de formação, e, portanto, os profissionais que mediam tal formação devem estar em pleno e contínuo desenvolvimento de suas capacidades, em constante revisão e atualização críticas de suas práticas pedagógicas. Entretanto, Gatti e Barretto (2009) advertem que a discussão sobre o locus não deve nunca obscurecer a questão primordial do debate na temática, que é a necessidade de se reformular a concepção de formação do professor.

No âmbito da formação de professores de nível universitário, mais especificamente os atuantes em licenciaturas, destacamos a importância que as concepções de profissionalidade docente possuem por impactarem diretamente o trabalho docente. Tais concepções influenciam, também, o modo pelo qual os conhecimentos subjacentes aos percursos formativos são promovidos dentro das práticas pedagógicas nos cursos de licenciatura, à medida que oferecem subsídios a uma prática profissional qualificada, reflexiva e significativa.

\section{METODOLOGIA}

A investigação seguiu a perspectiva qualitativa, uma vez que consistiu em um processo interpretativo sobre as perspectivas de desenvolvimento profissional de formadores de futuros professores, subjacentes às diretrizes das políticas e dos programas de formação docente viabilizadas pelo Ministério da Educação (MEC). Ou seja, a abordagem que nos orientou não sugere a medição ou aferição dos dados, mas sim, a análise qualitativa do material empírico e as possibilidades de significados que podem ser atribuídos a eles, pois foca o modo como a experiência social é criada e adquire significado (DENZIN; LINCOLN, 2006). 
O processo de constituição do material empírico consistiu em uma compilação das políticas e programas de formação continuada no ensino superior, encontrados nos sites da Coordenação de Aperfeiçoamento de Pessoal de Nível Superior (Capes), do Conselho Nacional de Desenvolvimento Científico e Tecnológico (CNPq) e do MEC. Essa etapa nos forneceu uma lista de documentos normativos que incentivam e regulamentam a formação docente tanto no nível de educação básica quanto superior.

Todos os sites visitados apresentam a funcionalidade de busca por descritor. $\mathrm{O}$ único descritor utilizado nas páginas destas instituições na internet foi "formação", sendo que procedemos à leitura e análise dos artefatos retornados mediante a busca realizada, buscando evidenciar as perspectivas à formação de formadores de futuros professores.

\section{DESENVOLVIMENTO PROFISSIONAL DO PROFESSOR DO ENSINO SUPERIOR}

Nossa análise apontou duas perspectivas de desenvolvimento profissional para o formador de futuros professores: (i) a universidade é lócus para o desenvolvimento do formador; (ii) o desenvolvimento do formador se concretiza mediante a realização de pesquisa e produção de conhecimento. Essas categorias são evidenciadas e discutidas neste texto de forma articulada, por se mostrarem entrelaçadas em sua natureza.

Ao recorrermos ao repositório do MEC, dois importantes documentos trouxeram subsídios para a discussão proposta neste texto: a Lei de Diretrizes e Bases da Educação (LDB) de 1996 e o Plano Nacional de Educação (PNE).

\section{LEI DE DIRETRIZES E BASES DA EDUCAÇÃO (LDB) DE 1996}

O Título IV da LDB - "Educação Superior" - é dedicado inteiramente a esse nível de ensino. No artigo 43, que abre o capítulo, estão definidas as atribuições da educação superior, fortemente ligadas aos ideais de difusão cultural, investigação científica e desenvolvimento intelectual dentro de uma perspectiva de formação profissional. Destaca-se, neste capítulo, o inciso VIII (incluído pela lei no 13.174, de 21 de outubro de 2015), que aborda especificamente o papel das Instituições de Ensino Superior (IES) na formação do profissional professor:

\footnotetext{
VIII - atuar em favor da universalização e do aprimoramento da educação básica, mediante a formação e a capacitação de profissionais, a realização de pesquisas pedagógicas e o desenvolvimento de atividades de extensão que aproximem os dois níveis escolares.
} 
Assim, indo ao encontro dos pressupostos encontrados em Zabalza (2004), a LDB confere ao ensino superior a responsabilidade pela formação do professor para atuação na educação básica. Outro destaque do capítulo IV da LDB é o início do artigo 54:

$\int 1^{\circ}$ No exercício da sua autonomia, além das atribuições asseguradas pelo artigo anterior, as universidades públicas poderão:

I - propor o seu quadro de pessoal docente, técnico e administrativo, assim como um plano de cargos e salários, atendidas as normas gerais pertinentes e os recursos disponíveis;

II - elaborar o regulamento de seu pessoal em conformidade com as normas gerais concernentes; [...].

De acordo com estas diretrizes, é assegurado às IES autonomia para compor seu quadro de pessoal docente, bem como propor planos de carreira e elaborar seus regulamentos de pessoal. Assim, na LDB, a questão da exigência ou fomento à formação continuada para o pessoal de nível superior fica a cargo de cada instituição e suas diretrizes regulamentadoras internas. Essa perspectiva aponta para a possibilidade de desenvolvimento profissional de formadores de professores a ser concretizada por meio de um trabalho integrado e institucional (GATTI; BARRETTO, 2009).

O Título VI da LDB - "Dos Profissionais da Educação"-, especificamente no parágrafo único do artigo 62 (incluído pela lei no 12.014, de 6 de agosto de 2009) aborda a formação dos trabalhadores da educação:

Parágrafo único. A formação dos profissionais da educação, de modo a atender às especificidades do exercício de suas atividades, bem como aos objetivos das diferentes etapas e modalidades da educação básica, terá como fundamentos:

I - a presença de sólida formação básica, que propicie o conhecimento dos fundamentos científicos e sociais de suas competências de trabalho;

II - a associação entre teorias e práticas, mediante estágios supervisionados e capacitação em serviço;

III - o aproveitamento da formação e experiências anteriores, em instituições de ensino e em outras atividades.

Destaca-se no inciso I uma perspectiva de formação de futuros professores centrada no desenvolvimento dos fundamentos da docência, abrangendo aspectos de natureza científica, social e profissional. O inciso II coaduna com os pressupostos de Roldão (2014), sobre a necessária articulação entre teoria e prática, e sugere que essa articulação seja promovida mediante vivências de ensino concretas e que se alargue para a formação continuada. De maneira análoga, o inciso III sugere também a valorização de experiências formativas e profissionais anteriores. 
Em conjunto, esses três incisos apontam para uma perspectiva de formação inicial de professores que se apresenta como uma primeira etapa do desenvolvimento profissional (NÓVOA, 1999; PONTE, 1994), cujas aprendizagens realizadas precisam ser ampliadas e aprofundadas posteriormente ao longo da carreira. Os incisos I e II, em específico, evidenciam que a promoção da formação inicial requer profissionais formadores munidos de conhecimentos e vivências profissionais que lhes permitam formar as futuras gerações de professores.

Relativamente ao inciso II, seria muito importante que a LDB fosse acatada neste sentido, entretanto, nem sempre tal articulação acontece, conforme assinalam Tanuri (2000) e Saviani (2009), ao desvelarem a tensão histórica existente nos cursos de formação docente. Essa tensão se expressa na alternância entre uma formação conteudista e eminentemente técnica em contraposição a uma formação instrumental, esvaziada de conhecimentos científicos e centrada unicamente em técnicas de ensino.

No artigo 62-A (incluído pela lei no 12.796, de 4 de abril de 2013), temos a primeira menção à expressão "formação continuada" da LDB:

Art. 62-A. A formação dos profissionais a que se refere o inciso III do art. 61 far-se-á por meio de cursos de conteúdo técnico-pedagógico, em nível médio ou superior, incluindo habilitações tecnológicas.

Parágrafo único. Garantir-se-á formação continuada para os profissionais a que se refere o caput, no local de trabalho ou em instituições de educação básica e superior, incluindo cursos de educação profissional, cursos superiores de graduação plena ou tecnológicos e de pós-graduação.

Assim, fica sob a responsabilidade da União oferecer formação continuada para os profissionais da educação em seus locais de trabalho, sobretudo em universidades. Para a discussão proposta neste texto são de especial interesse os artigos 65 e 66 da LDB, cuja redação, inalterada desde a original, reproduzimos a seguir:

Art. 65. A formação docente, exceto para a educação superior, incluirá prática de ensino de, no mínimo, trezentas horas.

Art. 66. A preparação para o exercício do magistério superior far-se-á em nível de pós-graduação, prioritariamente em programas de mestrado e doutorado.

A LDB primeiramente exime que a formação docente para o ensino superior contemple a prática de ensino, comumente conhecida como "estágio" e, na sequência, preconiza a preparação para a docência superior, prioritariamente, em cursos de pós-graduação stricto sensu. Entretanto, quanto a disciplinas, como "Didática do Ensino Superior" ou "Metodologia do Ensino Superior" e análogas, 
que tratam especificamente do método de ensino para a educação superior, inexistem garantias ou obrigações legais de que integrem os currículos de todos os programas de pós-graduação.

Em outras palavras, a LDB não obriga o professor de nível superior a efetuar estágio de docência para tal. E mesmo quando este estágio ocorre, não é suficiente. Assim, se ao futuro professor universitário é facultado o estágio de docência e muitos dos professores atuantes no ensino superior são, por formação inicial, bacharéis e não licenciados, supõe-se que esses profissionais poderão alcançar a formação pedagógica necessária mediante percursos formativos por eles definidos. Portanto, a perspectiva subjacente à LDB corrobora a concepção de desenvolvimento profissional que transcende o paradigma da superação das fragilidades dos processos formativos prévios (NÓVOA, 1999; PONTE, 1994), uma vez que concede maior autonomia ao docente universitário para delinear seu processo formativo ao longo da carreira, recorrendo ou não a processos formativos inerentes à docência.

Por outro lado, os estágios de docência, obrigatórios apenas para pósgraduandos bolsistas, não são garantia de aprendizagens profissionais relacionadas à dimensão pedagógica e didática da docência. De acordo com Pereira e Medeiros (2011), esses momentos formativos são muito mais de caráter observacional do que participativo, nos quais há pouco tempo e espaço para discussões aprofundadas sobre teorias ou metodologias pedagógicas.

Além disso, o artigo 67 da LDB preconiza que os sistemas de ensino deverão promover e valorizar os profissionais da educação, assegurando-lhes através de dispositivos, como estatutos e planos de carreira, alguns direitos, dos quais destacamos os incisos II, IV e V:

II - aperfeiçoamento profissional continuado, inclusive com licenciamento periódico remunerado para este fim; [...]

IV - progressão funcional baseada na titulação ou habilitação, e na avaliação do desempenho;

$\mathrm{V}$ - período reservado a estudos, planejamento e avaliação, incluído na carga de trabalho; [...].

É assegurado ao docente, independentemente do nível de educação no qual trabalha, direito ao aperfeiçoamento profissional contínuo, garantindo licenças periódicas remuneradas para tanto. A decisão do legislador pelas licenças converte-se, então, em subsídio legal que legitima a titulação do docente como base para a progressão funcional na sua carreira; preconiza, ainda, a reserva de períodos da própria carga de trabalho do docente para estudos, o que indica um movimento no sentido de incentivar que a formação não se desvincule da prática pedagógica cotidiana. 
Portanto, a concepção de formação subjacente à LDB transcende a dicotomia formação inicial-continuada (NÓVOA, 1999; PONTE, 1994), pois um amplo repertório de atividades, formais e informais, a qualquer tempo da carreira, caracteriza-se como processo formativo na perspectiva do desenvolvimento profissional docente (NÓVOA, 1999; PONTE, 1994; ROLDÃO, 2007).

\section{PLANO NACIONAL DE EDUCAÇÃO (PNE) DE 2014}

A versão mais recente do PNE é de 2014 (lei no 13.005, de 25 de junho de 2014). O artigo XXX institui as metas para o decênio 2014-2024, tanto na educação básica como na superior. A meta 12 é de elevar, até o fim do interstício, em $50 \%$ a taxa bruta de matrícula nas IES por jovens na faixa dos 18 aos 24 anos. No rol das estratégias que o PNE preconiza para alcançar a meta, destacamos:

12.14) mapear a demanda e fomentar a oferta de formação de pessoal de nível superior, destacadamente a que se refere à formação nas áreas de ciências e matemática, considerando as necessidades do desenvolvimento do País, a inovação tecnológica e a melhoria da qualidade da educação básica.

A meta 13 refere-se especificamente ao ensino superior, e dela consideramos importante frisar, pela menção direta aos cursos de formação de professores (pedagogia e licenciaturas), os seguintes aspectos:

Meta 13: elevar a qualidade da educação superior e ampliar a proporção de mestres e doutores do corpo docente em efetivo exercício no conjunto do sistema de educação superior para 75\% (setenta e cinco por cento), sendo, do total, no mínimo, $35 \%$ (trinta e cinco por cento) doutores.

Estratégias: [...]

13.4) promover a melhoria da qualidade dos cursos de pedagogia e licenciaturas [...] combinando formação geral e específica com a prática didática, além da educação para as relações étnico-raciais, a diversidade e as necessidades das pessoas com deficiência;

13.5) elevar o padrão de qualidade das universidades, direcionando sua atividade, de modo que realizem, efetivamente, pesquisa institucionalizada, articulada a programas de pós-graduação stricto sensu.

Também a meta 14 do PNE objetiva estimular a ampliação do número de mestres e doutores no país. No item 14.12, uma das estratégias desta meta é "ampliar o investimento na formação de doutores de modo a atingir a proporção de 4 (quatro) doutores por 1.000 (mil) habitantes." Essa estratégia remete à orientação da LDB sobre a formação continuada e periódica ser assegurada ao docente de nível superior, inclusive com direito a licenças remuneradas, encontrando o PNE respaldo e possibilidade de concretização em consonância com a LDB. Outra 
questão que chama a atenção quanto às metas 13 e 14 do PNE é que os fomentos ao aumento na quantidade de mestres e doutores no país apontam para uma interface com a promoção da pesquisa em nível de pós-graduação stricto sensu como estratégia de formação profissional do docente universitário.

A meta 18 do PNE assegura a existência de planos de carreira para os profissionais da educação básica e superior públicas. Duas das estratégias que visam o alcance dessa meta são:

18.2) implantar, nas redes públicas de educação básica e superior, acompanhamento dos profissionais iniciantes, supervisionados por equipe de profissionais experientes, a fim de fundamentar, com base em avaliação documentada, a decisão pela efetivação após o estágio probatório e oferecer, durante este período, curso de aprofundamento de estudos na área de atuação do(a) professor(a), com destaque para os conteúdos a serem ensinados e as metodologias de ensino de cada disciplina; [...]

18.4) prever, nos planos de carreira dos profissionais da educação dos Estados, do Distrito Federal e dos Municípios, licenças remuneradas e incentivos para qualificação profissional, inclusive em nível de pós-graduação stricto sensu.

Novamente, os dispositivos legais nos remetem à questão da formação continuada permanente, prevendo licenças remuneradas e outros subsídios para que o docente, independentemente do nível em que atue, possa dedicar-se integralmente a sua formação. É notável que para o PNE, a questão da formação é prioridade e está sempre vinculada ao ensino superior, em consonância com a LDB. O item 18.2 destaca, sobretudo, a necessidade de desenvolvimento profissional do docente da educação superior, especificamente o formador de futuros professores, que contempla o aprofundamento da formação prévia, bem como aprendizagens relacionadas a aspectos da docência, não desenvolvidos nos percursos formativos anteriores à docência na universidade.

As diretrizes e ações previstas no PNE apontam para uma ressignificação do paradigma de formação docente em âmbito nacional, na medida em que deslocam o foco desse processo da função exclusiva de preencher lacunas da formação inicial para a promoção do crescimento do docente e de fortalecimento de sua prática profissional (GATTI; BARRETO, 2009), mediante a realização de cursos de pós-graduação stricto sensu, realização de pesquisa científica e produção de novos conhecimentos. 


\section{CONSELHO NACIONAL DE DESENVOLVIMENTO CIENTÍFICO E TECNOLÓGICO (CNPQ)}

O CNPq, por sua vez, incentiva e promove a qualificação profissional e o desenvolvimento científico do país, mediante a implementação de bolsas e auxílios a estudantes e pesquisadores, a partir de programas de fomento à pesquisa científica. Essas ações, entretanto, têm foco voltado à produção de ciência e tecnologia do que efetivamente ao ensino e à docência. Entre os programas do CNPq, destacamos a página de bolsas e auxílio a pesquisadores de pós-graduação stricto sensu e o Programa de Iniciação Científica e Mestrado (PICME).

A seção de bolsas e auxílio do site descreve as modalidades e valores de incentivo que o CNPq oferece, enfatizando sempre o direcionamento dessas políticas de fomento à iniciação científica e ao desenvolvimento tecnológico (BRASIL, 2018a). Entretanto, como várias dessas bolsas destinam-se a subsidiar a realização de pós-graduação stricto sensu no Brasil ou no exterior (incluindo pósdoutoramentos), e dado o fato da preparação para a docência no ensino superior ocorrer, prioritariamente nesses cursos, conforme preconizado pelo artigo 66 da LDB de 1996, a distribuição de bolsas e auxílios constitui-se na principal via de promoção do desenvolvimento profissional dos formadores de futuros professores.

O PICME, além disso, oferece a estudantes universitários que se destacam nas Olimpíadas de Matemática, a oportunidade de realizarem estudos avançados em matemática simultaneamente à realização do curso superior, visando fortalecer a disciplina no Brasil por meio da concessão de bolsas de iniciação científica e bolsas de mestrado a esses estudantes. O programa é uma parceria entre o CNPq e vários órgãos, incluindo a Capes (BRASIL, 2018b).

Alguns itens encontrados na página do programa indicam sua forte relação com a formação do docente universitário. O primeiro deles é um dos três objetivos do programa, de: "fortalecer a formação de matemáticos e professores de Matemática" (BRASIL, 2018b). Na sequência, um dos critérios para que uma instituição se vincule ao PICME é que ela possua programa de pós-graduação na área de Matemática e/ ou Matemática Aplicada, recomendados pelas Capes. Assim, devido ao vínculo direto do PICME com a Capes e a pós-graduação, e novamente nos reportando ao disposto do artigo 66 da LDB, a oferta de bolsas de mestrado neste programa destaca-se como a principal (talvez a única) modalidade específica do $\mathrm{CNPq}$ voltada à formação de profissionais para a docência universitária em licenciaturas, especificamente na disciplina de Matemática. 
As ações do CNPq, portanto, sugerem uma perspectiva de desenvolvimento profissional, viabilizado pelo fomento à pesquisa e à produção de conhecimentos, como um processo contínuo ao longo da carreira, que se concretiza no contexto da universidade (ZABALZA, 2004). Essa perspectiva, além de evidenciar a natureza inconclusiva do desenvolvimento profissional docente, promovido mediante processos formais e informais de formação que associam aspectos da vida e do trabalho do professor (MARIN, 1995), aponta para uma ressignificação da noção de formação de formadores na medida em que os papéis assumidos por esses profissionais na universidade tornam-se mais amplos e complexos. Em outras palavras, a docência na universidade, ao sofrer influências da sociedade em transformação e colocar-se favor da produção de conhecimento e crescimento do país, amplia a atuação do professor, que recupera o papel de produtor de conhecimento.

\section{COORDENAÇÃO DE APERFEIÇOAMENTO DE PESSOAL DE NÍVEL SUPERIOR (CAPES)}

A Capes, enquanto órgão vinculado especificamente à formação e ao aperfeiçoamento do pessoal de nível superior, oferece maior número de programas e estratégias de fomento à formação do docente universitário. De modo similar ao CNPq, a Capes traz em seu site dados sobre seus programas de bolsas e auxílios para estudantes e de custeio para instituições e eventos. $\mathrm{Na}$ lista de "Programas Institucionais no País", encontram-se os programas ativos de concessão de bolsas e estímulos à formação e suas descrições mais detalhadas, dos quais destacamos aqueles de caráter ligado diretamente à pós-graduação stricto sensu e estágio pósdoutoral, novamente ressaltando a responsabilidade dada em lei dessa modalidade de ensino ser a responsável pela preparação de professores universitários, e sua interface com o elemento de incentivo à pesquisa como atividade formativa.

Além disso, na subpágina intitulada "Programas Estratégicos" são listados 37 ações e programas voltados ao aperfeiçoamento do pessoal de nível superior no país. Entretanto, apesar das diversas modalidades de fomento aos programas de mestrado e doutorado, bem como de incentivo aos docentes e discentes de pós-graduação, nenhuma dessas ações é especificamente voltada à docência ou à formação docente. Os programas priorizam distintas dimensões de desenvolvimento científico ou de inovação com vistas ao desenvolvimento do país, além de programas de incentivos à produção científica (periódicos e artigos). Destaca-se, também, nesta seção da página da Capes, ações com foco 
na premiação para estudantes de pós-graduação, que podem ser entendidas como estímulo à formação e qualificação do futuro docente enquanto discente de curso stricto sensu. Isto é, como incentivo à formação para o ensino superior.

Com relação aos programas ativos publicizados no site da Capes, que guardam correlação com a formação docente, especialmente em nível de pósgraduação stricto sensu, encontramos ações de bolsas e incentivos financeiros, como o programa de Demanda Social (DS), o Programa de Apoio à Pós-Graduação (PROAP), o Programa de Suporte à Pós-Graduação de Instituições de Ensino Comunitárias (Prosuc) e o Programa de Suporte à Pós-Graduação de Instituições de Ensino Particulares (Prosup), que concedem bolsas de auxílio financeiro para que mestrandos e doutorandos possam se dedicar exclusivamente à sua formação em nível de pós-graduação stricto sensu. De modo análogo, o Programa Nacional de Pós-Doutorado (PNPD) oferece bolsas para doutores em estágio pósdoutoral (BRASIL, 2018c). Assim como no CNPq, percebe-se que os incentivos à formação da Capes se vinculam, maioritariamente, à concessão de bolsas de estudos e auxílios financeiros.

Entretanto, a Capes tem fomentado ações que promovem a formação a partir da criação de cursos de pós-graduação temporários e/ou através de facilidades no afastamento do docente universitário para que possa obter um grau maior de titulação. Nesse sentido, destacamos o Doutorado Interinstitucional (Dinter) e o Programa de Formação Doutoral Docente (Prodoutoral), que são duas ações que visam incentivar a facilitar o acesso de docentes de nível superior com diploma de mestrado ao nível de doutorado. O Dinter custeia programas de doutorado de caráter temporário, conforme demanda específica e sob condições especiais, caracterizados pelo fato de parte das atividades de formação dos doutorandos vinculados ao programa serem desenvolvidas em instituição externa àquela em que atuam. Já o Prodoutoral, além da concessão de bolsas de estudos, favorece a mobilidade de pessoal de nível superior entre as IES para que obtenham grau de doutor, como forma de incentivar a formação docente universitária e atingir as metas previstas no PNE, referente ao quadro mínimo de doutores dos cursos de graduação de IES públicas (BRASIL, 2018c).

O Programa de Apoio a Eventos no País (PAEP), por sua vez, é uma iniciativa de custeio de eventos que objetiva impulsionar a realização de eventos científicos, tecnológicos e culturais de curta duração no país, destinados a pesquisadores, docentes e discentes dos programas de pós-graduação stricto sensu. Converte-se, desse modo, em incentivo financeiro à promoção de atividades formais de formação docente para nível superior, como simpósios, seminários, congressos, entre outras. Essas ações corroboram a perspectiva da formação 
de formadores, pautada na produção, socialização e reconhecimento dos conhecimentos produzidos no âmbito da pós-graduação, concebida com uma dimensão basilar do desenvolvimento profissional do docente universitário.

Além dos programas descritos, o site da Capes mantém histórico de programas descontinuados relativos à formação docente de pessoal universitário, dos quais também três se destacam: Mestrado Interinstitucional (Minter), Dinter Novas Fronteiras e o Programa de Consolidação das Licenciaturas (Prodocência). O primeiro é a versão do Dinter para facilitação à obtenção do título de mestre para docentes já atuantes em IES públicas; o segundo tratava-se de versão específica do Dinter, focada em estimular a abertura de programas de doutorados interinstitucionais em IES públicas das regiões Norte, Nordeste e Centro-Oeste do Brasil, carreando recursos específicos para tais localidades. Já o Prodocência, específico para as licenciaturas, visava o fomento financeiro à inovação e à elevação da qualidade dos cursos de formação de professores para a educação básica, em uma perspectiva de valorização da carreira docente superior e básica (BRASIL, 2018c).

A busca pelos programas da Capes revelou que há vários programas extintos e outros em processo de extinção. Algumas iniciativas de cursos de pósgraduação interinstitucionais vêm sendo sistematicamente descontinuadas, de modo que as bolsas e auxílios acabam por ser o principal foco, quando se trata de formação de pessoal para o nível superior. A descontinuidade do programa Prodocência é também questionável, visto que era o único programa do órgão com foco nas licenciaturas e cujos objetivos incluíam a "valorização da carreira docente". Entretanto, a avançarmos em 2020, essas ações têm sido fortemente atacadas, mediante cortes e suspensões de recursos em todos os programas.

Ainda de acordo com as informações disponíveis no site da Capes (BRASIL, 2018c), a instituição oferece incentivos financeiros na forma de premiações, como o "Prêmio Capes de Tese" e o "Grande Prêmio Capes de Tese", outorgados anualmente em reconhecimento às melhores teses de doutorado aprovadas nos cursos de pós-graduação em cada uma das 49 áreas do conhecimento. Em parceria com instituições públicas e privadas, esses prêmios constituem-se de valores financeiros, bolsas e incentivos para estágios pós-doutorais no Brasil e no exterior, premiando os alunos doutorandos e seus orientadores. Como destaque dentro da formação de formadores e do pessoal de nível superior para as licenciaturas, encontramos as premiações em menções honrosas especiais concedidas pela Fundação Carlos Chagas (FCC), dentro do "Prêmio Capes de Tese", para trabalhos específicos em duas frentes: educação e ensino. Tais prêmios constituem um importante incentivo financeiro não só à pesquisa no Brasil, mas também à docência em nível superior, ao contemplarem 
também os professores orientadores dos trabalhos selecionados. Além disso, é notável a parceria dos órgãos governamentais com outras instituições, inclusive de fundo privado, para angariar recursos para essas premiações.

Portanto, a análise sobre os programas e ações da Capes e CNPq apontam fortemente para uma perspectiva de profissionalidade docente inerente ao professor universitário, a qual valoriza a prática científica e a produção de novos conhecimentos, na medida em que privilegia o financiamento da pesquisa institucional e em nível de pós-graduação, assim como o reconhecimento dos trabalhos de maior destaque nas distintas áreas do conhecimento contempladas nesses programas. Esses aspectos apontam para a ressignificação do conceito de "formação continuada" nos programas em curso no Brasil, atribuindo-lhe o caráter de desenvolvimento profissional docente (GATTI; BARRETO, 2009). Essa perspectiva valoriza o profissional professor e o coloca no centro das atenções e intenções dos projetos oficiais e não oficiais de formação (GATTT; BARRETO, 2009), ao mesmo tempo em que valoriza a especificidade da atividade docente (SOTO et al, 2020) na educação superior, em especial na formação de futuros professores, vinculando esse processo à pesquisa.

Em síntese, a análise evidenciou duas perspectivas de desenvolvimento profissional para o docente da educação superior: a universidade constitui-se no locus principal para o desenvolvimento do formador de futuros professores na medida em que se constitui em contexto para realização de cursos de pósgraduação, programas de pós-doutorado, realização de parcerias institucionais ou interinstitucionais, assim como por oportunizar ao professor formador diferentes experiências profissionais em nível de ensino e pesquisa; o desenvolvimento do formador se concretiza mediante a realização de pesquisa e produção de conhecimento, na medida em que os incentivos se concentram na distribuição de bolsas de pesquisa e pós-graduação, premiação de trabalhos com reconhecida contribuição para as áreas contempladas com esses programas, realização de eventos e criação de periódicos para a divulgação do conhecimento produzido mediante esses incentivos.

Embora o ordenamento legal analisado priorize, de alguma maneira, a formação de professores universitários, as ações previstas assumem o caráter de formação para pesquisa, constituindo-se em um aspecto muito particular da profissionalidade docente do formador de outros professores. Nessa perspectiva, a formação do formador de futuros professores abarca: o domínio conceitual e prático da docência (GATTI; BARRETO, 2009; ROLDÃO, 2014) na educação superior e na educação básica; o envolvimento e compromisso dos formadores 
com a formação dos futuros professores; assim como o domínio e as condições para o desenvolvimento científico (produção de pesquisa e de conhecimento) nas áreas em que esses profissionais atuam.

Essa perspectiva de formação de formadores de professores, que efetivamente caracteriza o processo de desenvolvimento profissional de professores (NOVÓA, 1999; PONTE, 1994), solicita uma concepção de profissionalidade docente ampliada e coerente, a qual evidencie a especificidade da docência em cursos de formação de professores em tempos de mudança. Ou seja, uma profissionalidade que considere os distintos elementos necessários à prática docente (ROLDÃO, 2014) em cursos de licenciatura, que tem ao mesmo tempo um duplo compromisso: formar para a docência na educação básica e formar para a pesquisa. Portanto, pensar processos formativos com foco em desenvolvimento profissional docente para o formador de futuros professores significa fomentar ações e atividades em que o professor possa tornar-se sujeito ativo e central na apropriação de conhecimentos necessários à sua prática profissional. Além disso, essas ações precisam estar apoiadas e voltarem-se para as especificidades da profissionalidade docente em cursos de formação de futuros professores, bem como promover reflexões sobre as potencialidades e fragilidades desse processo em um contexto social, político e econômico em transformação.

\section{CONSIDERAÇÕES FINAIS}

No Brasil, as perspectivas de desenvolvimento profissional de formadores de futuros professores, evidenciadas mediante a análise sobre as diretrizes educacionais para o ensino superior (LDB e PNE) e dos programas e ações da Capes e do CNPq são: a universidade constitui-se em locus principal e privilegiado de desenvolvimento profissional do formador de futuros professores; e o desenvolvimento do formador se concretiza mediante a realização de pesquisa, produção de conhecimento, divulgação e reconhecimento do conhecimento produzido. Essas duas perspectivas, indissociáveis entre si, uma vez que a produção de conhecimento é inerente à universidade, desvelam uma concepção mais alargada da profissionalidade docente em cursos de licenciatura (voltados à formação de futuros professores. Essa concepção valoriza a atividade docente universitária vinculada à pesquisa e produção de conhecimento, ao mesmo tempo em que resgata e valoriza a universidade como lugar para o crescimento pessoal e profissional dos professores, que assume uma dupla função nesse nível de ensino: formar para a profissão e para a pesquisa. 
Além de evidenciar a natureza inconclusiva e dinâmica do processo de desenvolvimento profissional docente, essa perspectiva aponta para uma ressignificação do conceito de formação de formadores de futuros professores na medida em que os papéis assumidos por esses profissionais na universidade tornam-se mais amplos, plásticos e complexos. Em outras palavras, a docência na universidade, ao sofrer influências da sociedade em transformação e colocar-se a favor da produção de conhecimento e crescimento do país, amplia o papel do professor, que se torna produtor, disseminador e crítico do conhecimento.

\section{REFERENNCIAS}

ALVARADO-PRADA, L. E. The school as a whole in the countinuing education of theachers. In: RAYMOND, D. Noveaux espaces de développement professionel et organisationnel. Canada: Éditions du CRP, 2001. p. 85-99.

GATTI, B. A.; BARRETTTO, E. S. S. (coord.) Professores do Brasil: impasses e desafios. Brasília: Unesco, 2009.

NÓVOA, A. Os professores na virada do milênio: do excesso dos discursos à pobreza das práticas. Educação e Pesquisa. São Paulo, v. 25, n. 1, p.11-20, jan./ jun. 1999.

NÓVOA, A. Esboço de um modelo de análise da profissão docente. In: NÓVOA, A. Profissão professor. 2 ed. Porto: Porto Editora, 2003. p. 22-31.

PEREIRA, E. F.; MEDEIROS, C. C. C. Metodologia do ensino superior nos programas de pós-graduação stricto sensu em Educação Física no Brasil: a formação docente em questão. Movimento. Porto Alegre, v. 17, n. 4, p. 165-183, out./dez. 2011.

PONTE, J.P. O Desenvolvimento profissional do professor de matemática. Educação \& Matemática. Lisboa, n. 31, p. 9-20, jul./set. 1994.

ROLDÃO, M.C. Currículo, didáticas e formação de professores: a triangulação esquecida. In: OLIVEIRA, M.R. (Org.). Professor: formação, saberes e problemas. Porto: Porto Editora, 2014. p. 91-104. 
ROLDÃO, M.C. Formação docente: natureza e construção o conhecimento profissional. Revista Brasileira de Educação. São Paulo, v. 12, n. 34, p. 94-103, jan./abr. 2007.

SAVIANI, D. Formação de professores: aspectos históricos e teóricos do problema no contexto brasileiro. Revista Brasileira de Educação, v. 14, n. 40, p. 143-155, jan./abr. 2009.

SOTO, G. et al. I don't know! What do you think? Why? Collaborative work between primary and secondary school teachers. In: BORKO, H.; POTARIICMI, D. (ed.). ICMI Study 25: conference proceedings - Teachers of Mathematics Working and Learning in Collaborative Groups. Lisboa, 2020.

ZABALZA, M. A. O ensino universitário: seu cenário e seus protagonistas. Porto Alegre: Artmed, 2004.

\section{Adriana Richit}

Doutora em Educação Matemática - UNESP

Pós doutorado - Instituto de Educação, Universidade de Lisboa

Professora, Classe D, nível Associado II, da Universidade Federal da Fronteira Sul - UFFS

Campus de Erechim - Erechim, RS

Docente do Programa de Pós-graduação em Educação da UFFS

Coordenadora do Grupo do Estudos e Pesquisa em Educação Matemática e Tecnologias-GEPEM@T

E-mail: adrianarichit@gmail.com

\section{William Xavier de Almeida}

Mestre em Educação pela Universidade Federal da Fronteira Sul. Servidor da Universidade do Estado de Santa Catarina (UDESC), Campus Chapecó. Membro do Grupo de Estudos e Pesquisa em Educação Matemática e Tecnologias (GEPEM@T).E-mail: wxalmeida89@gmail.com 